\title{
A administração da ciência e tecnologia proposta para o Distrito Federal
}

Sérgio de Almeida Bruni, economista, pósgraduado em Administração Pública pela Fundação Getúlio Vargas - FGV e especialista em Empresas Estatais pelo Institut International d'Administration Publique (Paris), ex-supervisor de Programas de Pesquisas do CNPq e do Governo do Distrito Federal. Atualmente é superintendente da Área de Planejamento da

Funcep.

O presente trabalho é resultado de uma pesquisa, realizada pelo economista Sérgio Bruni, excoordenador do Programa de Ciência e Tecnologia do Governo do Distrito Federal, cujo objetivo é propor formas de acionamento e coordenação para as atividades de CET no Distrito Federal e Região Geoeconômica de Brasília.

Encontra-se adequado à nova proposta de trabalho do Conselho Nacional de Desenvolvimento Científico e Tenológico - CNPq, no sentido de desconcentrar as ações de C\&T do nível federal para o estadual e o municipal, conforme Decreto n. 75.225.

Visando materializar este plano de ação, o CNPq propôs que os estados e o Distrito Federal se organizassem sob a forma sistêmica, tendo em vista propiciar seus ajustamentos ao Sistema Nacional de Desenvolvimento Científico e Tecnológico SNDCT, sem, entretanto, desfocar suas realidades e anseios locais.

\section{Considerações}

O que pretendemos apresentar, com este tra-
Sérgio de Almeida Bruni

balho são idéias de como a administração do componente ciência e tecnologia no Distrito Federal, efetuada de maneira coordenada, buscando a eficácia, eficiência e efetividade, pode auxiliar o governo do Distrito Federal a encontrar soluções para problemas crônicos ou emergentes, possibilitando a geração de empregos, nesta época de escassez, bem como contribuir para o desenvolvimento das questões cientificas e tecnológicas no Planalto Central, com, inclusive, a perspectiva de sua transferência para as regiões limítrofes, como é o caso da geoeconômica de Brasília.

Acreditamos que, em função da corporificação dos objetivos expostos seja necessário pensar de forma sistêmica, criar e estruturar uma administração de C\&T, visando suprir a lacuna existente no manuseio dos mecanismos capazes de implementar as mudanças pretendidas.

Assim, tendo em mente a assertiva do professor Marcovitch, de que a "ciência corresponde ao saber; a tecnologia ao fazer; a pesquisa, à busca do desconhecido", nossa intenção é que a proposta administração de CधT tenha por meta fazer algo que 
não está sendo feito, ou fazê-lo de maneira mais eficaz e racional.

\section{Marcos de referência}

Os marcos de referência para o delineamento e a operacionalização da aludida estrutura são o Plano de Governo do Distrito Federal e o III Plano Básico de Desenvolvimento Científico e Tecnológico III PBDCT.

As constantes mutações observadas em nosso país no que concerne à busca de novas técnicas, novos processos, possibilitou que nas últimas décadas a evolução das questões científicas e tecnológicas se fizessem sentir de maneira vigorosa, mas este surto não foi acompanhado da esperada transferência para o setor produtivo das inovações aqui desenvolvidas ou adaptadas do exterior.

Assim, procurou-se, após análise dos fatos, um redesenho do aparato do planejamento de C\&T, mais precisamente no Sistema Nacional de Desenvolvimento Científico e Tecnológico - SNDCT, o qual não mais deveria ser o único responsável pela coordenação nacional do componente C\&T. Para o entendimento das propostas do trabalho, a seguir faremos um breve relato do que vem a ser o SNDCT e o PBDCT.

\section{Síntese a respeito do SNDCT}

O SNDCT foi criado inspirado na necessidade de um fluxo coordenado e sistematizado de ações, diretrizes e estratégias voltadas para o desenvolvimento da ciência e da tecnologia em nosso país.

Em janeiro de 1975, o presidente Geisel assinou o Decreto n. 75.225 que visava organizar formalmente o SNDCT, orientando e estruturando sua atuação a nivel federal, determinando, identicamente que se criassem nos ministérios, com atuação significativa na área de C\&T, órgãos setoriais, que tivessem a verossimilhança de secretarias de tecnologia.

Pelo mesmo instrumento, foi decretado que ao Conselho Nacional de Desenvolvimento Científico e Tecnológico - CNPq competia auxiliar o ministrochefe da Secretaria de Planejamento da Presidência da República - Seplan/PR no desempenho de suas atribuições, principalmente na formulação da política nacional de C\&T; na coordenação da elaboração do PBDCT, bem como no seu acompanhamento; na articulação com os estados, territórios, Distrito $\mathrm{Fe}$ deral e municípios, visando à compatibilização de esforços.

Foi também regulamentado que para a execução do PBDCT o principal instrumento financeiro se. ria o Fundo Nacional de Desenvolvimento Científico e Tecnológico - FNDCT, instituído em 1969, não se caracterizando, porém, como fonte única e exclusiva de recursos para a agilização da política de desenvolvimento científico e tecnológico, sendo complementado com as dotações de outras fontes financeiras dos demais órgãos do sistema.

Somente após a transformação, em 1974, do então Conselho Nacional de Pesquisas - $\mathrm{CNPq}$, em fundação, é que a estrutura do SNDCT começou a ser corporificada.

Assim, observamos que diversos ministérios já implantaram as suas secretarias, departamentos ou subchefias de ciência e tecnologia, atendendo à determinação do Decreto n. 75.225 , e outros, no momento, estudam o assunto.

Além disso, é de fundamental importância ressaltar que os estados e territórios já estão se organizando sob forma sistêmica, visando tratar o componente C\&T no nível preconizado.

A estrutura do SNDCT é constituída de : órgão central (o CNPq); órgãos setoriais (as secretarias, departamentos e subchefias dos diversos ministérios); órgãos seccionais laqueles que, no âmbito dos diversos ministérios, realizam atividades relacionadas com ciência e tecnologia).

\section{$O$ que é o PBDCT}

O PBDCT, instituído através do Decreto n. 70.553 , de 1972 , é um instrumento de previsão, orientação e coordenação nacional, com um orçamento-programa trienal, revisto a cada ano. É elaborado pela Seplan, em articulação com o CNPq e submetido à aprovação do presidente da República.

Para a sua elaboração, o CNPq, conta com o apoio de diversos órgãos governamentais e privados, associações científicas e elementos da comunidade técnico-científica e empresarial, submetendo a aprovação do seu texto final ao Conselho Científico e Tecnológico - CCT. Hoje, já temos o III PBDCT, que fixa a política de C\&T para o período de 1980-1985.

Os pilares básicos deste documento são seus discursos sobre capacitação científica e autonomia tecnológica.

Em seu capitulo terceiro, sob o título "Instrumentos de Ação", encontramos tópicos específicos sobre coordenação de atividades; planejamento de ciência e tecnologia; instrumentos normativos, fiscais e creditícios; e cooperação internacional.

\section{Ambiente de estudo}

O governo do Distrito Federal, apesar das facilidades inerentes à proximidade com os mais diversos órgãos federais, privados e naturalmente de 
seu próprio complexo administrativo, sempre atuou ineficazmente, em relação ao desenvolvimento articulado de programas científicos e tecnológicos.

Pretendemos, com o presente trabalho, propiciaruma visão panorâmica de como a administração do componente C\&T pode subsidiar a política de desenvolvimento do Distrito Federal e adjacências, pois a nosso ver, a premissa básica para a consolidação de Brasília como Capital Federal, é que se integre harmonicamente o eixo político-administrativo ao cultural-científico e tecnológico do país.

Essa preocupação busca privilegiar critérios decisórios, adaptados à realidade nacional indo ao encontro de uma maior eficácia nos assuntos públicos.

O primeiro eixo, ou seja, o político-administrativo, vem sendo direcionado adequadamente, visto que Brasília já é reconhecida como a frente das decisões político-administrativas nacionais. Falta, entretanto, essa representatividade se firmar ao aspecto cultural, científico e tecnológico.

Ao distrito Federal cabe um importante papel na integração cultural-científica e tecnológica do país e, tendo em vista o elevado grau de especialização de mão-de-obra nas diferentes áreas do conhecimento, se poderia pensar, a nível nacional, em implementar segmentos, institutos, fundações, etc., dedicados ao estudo, treinamento e difusão de conhecimentos técnicos e científicos, que aqui poderão se concentrar.

Como é sabido, a entidade coordenadora, em âmbito nacional, dos aspectos ligados à ciência e tecnologia e o CNPq, cuja sede e a administração central estão aqui localizadas e devido à multiplicidade de suas atribuições e em consonância com a diretriz governamental procedente da Seplan, no sentido de descentralizar as atividades de C\&T no país, tem procurado apoiar as questões específicas às realidades locais.

Com a intenção de se descentralizar a C\&T, foi criado um programa de cooperação técnica com a Secretaria de Articulação com os Estados e Municípios - Sarem, da Seplan, e o CNPq, que objetiva estimular o estudo e a institucionalização em todo o país, dos Sistemas Estaduais de C\&T, que nada mais são do que a administração com eficácia e efetividade das questões científicas e tecnológicas locais.

O Distrito Federal, a nosso ver, deve se incorporar rapidamente a esse esforço de integração dos eixos mencionados e à política de descentralização de C\&T, preconizada pela Seplan, visando melhor conhecer sua infra-estrutura de C\&T e estudar formas de incorporá-la ao espaço do seu planejamen- to e áreas de influência, como a região geoeconômica de Brasília.

\section{As demandas isoladas}

Enquanto estados com processo de desenvolvimento menos intenso já procuram conceber mecanismos de administração para coordenare fomentar, sem paralelismos ou pluralidade de tratamento, suas ações em C\&T, o governo do Distrito Federal permanece alheio a esse esforco nacional e somente esporadicamente, percebemos alguma preocupação com a questão por parte de entidades pertencentes a seu complexo administrativo.

Embora muitas instituições do governo do Distrito Federal explicitassem suas demandas por conhecimentos técnico-científicos, devido à necessidade de aprimorar-se frente aos novos desafios surgidos, como a biotecnologia, as tecnologias de cerrado, de pavimentação, de saneamento, habitação e outras, observou-se que esse esforço era isolado, não existindo nenhum mecanismo de administração que coordenasse o processo global.

\section{A administração de C\&T}

$\mathrm{O}$ que chamamos de administração de C\&T para o Distrito Federal é o instrumento, que viria possibilitar o diagnóstico da função CधT e indicar caminhos organizacionais que se acoplem com os federais, sem, no entanto, descaracterizar suas peculiaridades locais.

Esta visão foi transmitida ao então sr. governador Aimé Lamaison e ao sr. secretário do Governo, Renan D'Ávila Duarte, em fins de 1981 e, nos primeiros meses de 1982, interessados em um detalhamento maior do assunto, contactaram o $\mathrm{CNPq}$, que colocou o autor deste trabalho à disposição do governo do Distrito Federal por alguns meses para desenvolver o tema, surgindo, assim, um pequeno núcleo, composto pelo autore dois assistentes, ambos dos quadros locais, que durante alguns meses estudaram o assunto, oferecendo então, subsídios para 0 tema.

\section{O início do estudo}

Coube à Secretaria do Governo, como órgão central de planejamento do governo do Distrito Federal, o apoio aos trabalhos então iniciados, os quais se iniciaram em fevereiro de $1982 \mathrm{e}$ findaram em setembro do mesmo ano.

As ações iniciaram-se pela sensibilização das autoridades locais, aí incluídos secretários de Estado do Distrito Federal, presidentes e diretores de instituições de seu complexo administrativo, gerentes e coordenadores de áreas das diversas repartições públicas locais, estendendo-se, através de palestras, 
folhetos e reuniões setoriais, a técnicos que pudessem se utilizar da perspectiva emergente.

O passo seguinte, foi a verificação de entidades existentes no Distrito Federal que realizam pesquisas e quais as que poderiam vir a realizá-las. Assim, propusemos o cadastramento das entidades atuantes em C\&T não limitando seu universo aos órgãos do complexo administrativo local, pois também a esfera federal deveria ser listada, caso o produto de seus trabalhos científicos e tecnológicos se destinasse à população do Distrito Federal, além das empresas privadas que aqui prestassem serviços de pesquisa.

Elaboramos, em conjunto com a Empresa Brasileira de Pesquisa Agropecuária - Embrapa, com recursos oriundos do CNPq e da Secretaria de Tecnologia Industrial - STI, do Ministério da Indústria e Comércio, questionário e manual de instruções, e treinamos estagiários a fim de efetuarmos o cadastramento, o qual se corporificou no documento Diretório de Entidades Atuantes em Ciência e Tecnologia no Distrito Federal.

Através deste trabalho constatamos a existência de mais de uma centena e meia de organizações que, de alguma forma produziam C\&T, o que nos levou a insistir na necessidade de institucionalização, no Governo do Distrito Federal, de um mecanismo capaz de administrar, armazenar, fomentar e difundir toda essa gama de conhecimentos produzidos e em produção, bem como estimular a ampliação das áreas de conhecimento.

\section{A estrutura organizacional de C\&T para o Distrito Federal}

Ao iniciar o esboço da estrutura pretendida nossa fonte de referência foi a observação de Caravantes, no sentido de que "as estruturas são criadas ou modificadas para agilizarem o processo decisório, mas na maioria das vezes, se constituem, elas próprias, em fatores disfuncionais naquele setor".

Assim, em consonância com as diretrizes federais, e já de posse de dados significativos sobre a realidade e a cultura organizacional do Distrito Federal aqui preconizadas, visualizamos o setor sob a forma de um Sistema de Ciência e Tecnologia do Distrito Federal.

Ta! sistema deverá ser composto de: Conselho de Ciência e Tecnologia, como órgão decisório de alto nível; Secretaria-Executiva do Conselho, como órgão operacional de toda a política concebida para o setor; instituições públicas e privadas que atuem na área de C\&T e cujo universo de ação seja o Distrito Federal ou a Região Geoeconômica de Brasília.

\section{O projeto do sistema de C\&T do Distrito Federal}

Nosso entendimento sobre sistema, em termos de definição, é o preconizado por Hanika, quando ele nos diz ser um sistema "qualquer entidade conceitual ou física, composta de partes interrelacionadas, interatuantes ou interdependentes'.

Em nosso caso específico, a assertiva comporta as dimensões de inter-relacionamento, interatuação e de interdependência, conforme veremos a seguir.

Ainda como um marco de referência de nossa postura, no que concerne aos contornos do sistema de C\&T, devemos enfatizar tratar-se de um sistema aberto, na acepção do explicitado por Kleber Nascimento quando ele nos diz que o mesmo "pode ser compreendido como um conjunto de partes de constante interação (o que ressalta a característica da interdependência das partes) orientado para determinados propósitos (com um comportamento teleológico, orientado, portanto, para fins) e em permanente relação de interdependência com o ambiente externo lessa interdependência há que ser entendida como a dupla capacidade de influenciar o meio externo e ser por ele influenciado)".

Assim, tendo como meta o desenvolvimento harmônico dos aspectos sócio-econômicos de nossa Capital Federal, o sistema em foco procurará estimular, fomentar e apoiar a realização de pesquisas em todas as áreas de interesse da comunidade local.

Seu foco será sempre o homem, o atendimento de suas necessidades básicas e seu bem-estar. Sua política, que se corporificará através de um plano de ação, será desenhada participativamente, buscando privilegiar ações prioritárias, consistentes, os reclamos da população do Distrito Federal.

Além desse macrofoco, a capacitação científica e tecnológica, a integração de entidades de pesquisas, a proteção ao meio ambiente, a maior integração entre o setor produtivo e a CधT são as metas esperadas, dentre outras.

Tudo isto deverá, como dissemos, decorrer da interação do governo local com a comunidade científica e a própria população, num pool onde a mão dupla deverá ser ativamente utilizada em prol da viabilidade do processo.

O projeto do sistema comporta entidades públicas, de administração direta e indireta, voltadas para o desenvolvimento da ciência e tecnologia bem como todas as instituições cujo objetivo seja a pesquisa - básica ou aplicada - , na área do Distrito Federal ou externa ao mesmo, mas que desenvolvam atividades de interesses da Capital Federal. 
Conforme bem ressalta o documento Sistemas Estaduais de Ciência e Tecnologia: concepção e diretrizes operacionais, do CNPq, o PBDCT, criado pelo Decreto Federal n. 75.225, não deve apenas se pautar pela formalidade emanada de seus órgãos superiores, em especial o CNPq, mas também pelos anseios da comunidade nacional, levando em conta as potencialidades locais.

É inconteste que, até o presente, apesar do esforço empreendido, o PBDCT não logrou êxitos pretendidos, quando de sua criação, pois falhou, sobretudo, na integração dos recursos de que dispõe para o desenvolvimento científico-tecnológico com os anseios e recursos dos estados, dos territórios, do Distrito Federal e municípios, bem como dos setores produtivos dessas regiões.

O cerne da questão hoje é o reforço ou a implantação e operacionalização, dentro de uma metodologia comum, porém respeitando suas características próprias, dos Sistemas Estaduais de C\&T.

Assim, objetivando o aproveitamento sistematizado e eficaz das potencialidades da nossa Capital Federal e cumprindo as diretrizes governamentais no sentido de desconcentrar o SNDCT, este estudo tem por finalidade servir como marco de referência para reflexão sobre a problemática de C\&T, em adequação com a realidade e cultura do Distrito Federal.

\section{O Conselho de Ciência e Tecnologia do Distrito Federal}

Nosso entendimento é de que o CCT/DF deva ser o órgão máximo no processo decisório, dentro do Sistema de C\&T do Distrito Federal, devendo formular e implementar a política científica e tecnológica da Capital da República.

O CCT/DF tem por funções:

- implementar no Distrito Federal, o Plano Básico de Desenvolvimento Científico e Tecnológico;

- articular o intercâmbio entre os diversos órgãos governamentais e privados que, direta ou indiretamente, utilizam, desenvolvam ou apóiam no Distrito Federal, atividades ligadas à pesquisa e desenvolvimento, inovação tecnológica; transferência de tecnologia, serviços científicos, formação de pessoal para C\&T e produção e consumo de bens e serviços;

- coordenar, acompanhar e controlar as atividades de ciência e tecnologia do Distrito Federal;

- incentivar a pesquisa científica e tecnológica nos setores público e privado do Distrito Federal;

- estimular a realização de cursos, estudos, estágios, seminários, conferências e divulgação de assuntos relacionados com o desenvolvimento e a pesquisa científica e tecnológica;

- acompanhar a evolução científica e tecnológica a fim de identificar novas áreas de pesquisas e fortalecimento de outras já existentes:

- coordenar a negociação para a concessão de apoio técnico e financeiro a projetos de C\&T de entidades públicas e particulares, supervisionando a sua aplicação;

- coordenar a elaboração e acompanhar a implementação do PBDCT/DF;

- promover a realização de acordos e convênios com entidades públicas e privadas, tendo em vista o cumprimento das finalidades da administração de C\&T do Distrito Federal;

- avalizar tecnicamente todos os convênios, contratos ou termos aditivos na área de C\&T que os órgãos da administração direta ou indireta do Distrito Federal vierem a assinar.

\section{A operacionalização do Sistema de C\&T do Distrito Federal}

Visualizamos a Coordenação do Sistema C\&T/DF como a cabeça do sistema, e para utilizarmos o jargão dos demais estados, daremos a esta coordenação, como foi dito anteriormente, o nome de Secretaria-Executiva do Sistema de Ciência e Tecnologia do Distrito Federal-SECT/DF.

O sistema será integrado inicialmente pela Secretaria do Governo, por todas as secretarias setoriais, bem como pelos demais órgãos do complexo administrativo, que possuam ou venham a possuir, em seus estatutos, a função C\&T, bem como pelas demais entidades que tratem da questão no Distrito Federal.

O relacionamento da SECT com as demais secretarias e órgãos do complexo administrativo será efetuado da seguinte maneira:

- secretarias setoriais - o interface será o chefe de Gabinete, a quem caberá encaminhar a documentação específica de C\&T para a coordenação do Sistema de C\&T e para os órgãos vinculados à respectiva Secretaria Setorial. Cabe ressaltar que no gabinete das secretarias deverá existir um elemento que trate das questões de C\&T, subsidiando, assim, ao chefe de Gabinete nos assuntos que mereçam exame por parte deste. Tal servidor será treinado e orientado inicialmente pela coordenação do Sistema de C\&T, sendo que periodicamente haverá reuniões setoriais, onde este poderá externar suas necessidades e anseios. Cabe, também, frisar que para cada área temática poderemos contar com um comitê assessor específico, por exemplo: Comitê Assessor de Agricultura, Comitê Assessor de Saúde Pública, etc.

Tais comitês serão, em princípio, formados por sete elementos, assim dispostos: coordenador do Sistema de C\&T/DF, três técnicos do complexo ad. ninistrativo, com experiência e conhecimentos téc- 
nicos reconhecidos e indicado(s) pelo(s) secretário(s) da(s) área(s) temática(s) e três pesquisadores de notório saber, indicados pelo Conselho de Ciência e Tecnologia. Estes comitês terão um presidente, eleito dentre os seus participantes, só não podendo ser escolhido o coordenador de CधT, e a vigência de seus mandatos será de dois anos, com direito à recondução.

- Órgãos do complexo administrativo do Distrito Federal - o interface será sempre o responsável pelo setor de pesquisas da entidade. Caberá a ele articular-se com o interface setorial para traçar metas e propor medidas no campo da C\&T, bem como assessorá-lo em questões específicas. Será o supervisor de acompanhamento dos projetos de CधT que estiverem se desenvolvendo em sua instituição.

- Órgãos externos ao governo do Distrito Federal - O relacionamento se fará, salvo casos excepcionais, com os dirigentes das entidades.

\section{A Secretaria-Executiva do Conselho}

Julgamos que a Secretaria-Executiva do Conselho deva ser desempenhada por uma coordenação de CधT, vinculada à Secretaria do Governo, tendo em vista que esta se reveste do caráter de entidade de planejamento e coordenação no âmbito do governo local.

Tal estrutura, que deve ser ágil e leve, deverá ter as seguintes atribuições: operacionalizar todas as diretrizes vindas do CCT/DF; acompanhar os programas e projetos desenvolvidos pelo sistema, estar ciente das atividades desenvolvidas pelos demais sistemas estaduais, bem como dos programas do SNDCT; estruturar e manter subsistemas específicos; articular-se com órgãos usuários e executores de CधT, com ênfase para as instituições universitárias e órgãos de pesquisa; consolidar o orçamento do governo do Distrito Federal para a função C\&T; promover o entrosamento entre as instituições de pesquisa local, as universidades e o setor produtivo; apresentar relatório técnico ao CCT/DF.
Caberá à Gerência de Projetos, como órgão de assessoramento da Coordenação de C\&T/DF, o exame das consultas prévias sobre o encaminhamento de projetos para o apoio técnico e financeiro; a supervisão e articulação da formação de recursos humanos, em colaboração com universidades, instituições isoladas de ensino superior e entidades de pesquisa, bem como apoiar administrativamente a atuação dos comitês assessores das diversas áreas do conhecimento.

Quanto à Gerência de Apoio à Pesquisa, esta terá por finalidade coletar e analisar dados para a elaboração da programação em C\&T; confeccionar e manter atualizados os cadastros das instituições de pesquisa existentes; promover a divulgação das informações cadastradas em C\&T para as entidades interessadas; identificar fontes de apoio técnico e financeiro a projetos de C\&T; coletar e tratar as informações que interessem aos investimentos do Distrito Federal quanto à atividade científica e tecnológica; articular-se ou promover a articulação com institutos de pesquisas do país ou órgãos técnicos especializados, objetivando o intercâmbio, desenvolvimento e melhoria de execução de suas atividades; adotar, no que for pertinente, as normas técnicas para o setor de ciência e tecnologia, estabelecidas pelo CNPq; elaborar e propor normas sobre execução e melhoramento dos projetos de C\&T; elaborar quadros, mapas e tabelas demonstrativos de evolução do Sistema CET/DF; analisar e diagnosticar aspectos defasados no referido sistema; elaborar relatórios de trabalhos realizados com vistas à publicação, quando comprovada a sua validade para o Sistema; supervisionar o Fundo de Incentivo à Pesquisa Tecno-Científica do Distrito Federal.

Resumindo, a estrutura do Sistema C\&TDF seria a seguinte:

- Conselho de Ciência e Tecnologia;

- Secretaria-Executiva, desempenhada pela Coordenação de C\&T da Secretaria do Governo do Distrito Federal;

- entidades públicas, da administração direta

Coordenação

Gerência

de Projetos

Gerência de

Apoio à Pesquisa

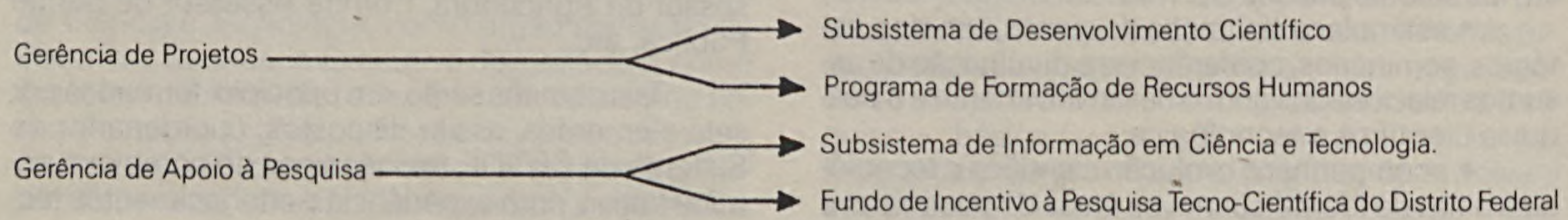


e indireta, voltadas para o desenvolvimento científico e tecnológico e entidades que a esse fim se dediquem.

\section{Conselho de Ciência e Tecnologia do Distrito Federal}

Éo órgão máximo dentro do Sistema C\&T/DF, destinado a estabelecer diretrizes e formular a política de ciência e tecnologia do Distrito Federal, bem como coordenar, acompanhar e controlar as atividades referentes ao desenvolvimento científico e tecnológico.

É composto por doze membros: secretário do Governo, na qualidade de presidente; um representante da Secretaria de Educação e Cultura; um representante da Secretaria de Serviços Sociais; um representante da Secretaria de Saúde; um representante da Secretaria de Serviços Públicos; um representante da Secretaria de Agricultura; três representantes da comunidade local; três representantes da comunidade científica, com notório conhecimento e experiência no assunto.

A organização do Conselho é a seguinte: Plenário; Comitê-Assessor; secretário-executivo.

O plenário é o órgão colegiado diretivo e deliberativo do Conselho, que tem as competências de: instruir comissões, deliberar sobre assuntos do sistema, elaborar e alterar o regimento interno, apreciar o orçamento anual de C\&T e deliberar sobre propostas de execução de planos, programas e projetos de C\&T. O Plenário se reunirá bimestralmente.

O Comitê Assessor poderá ser constituído especificamente, a fim de atender a determinados segmentos da área de C\&T, quando o Plenário julgar necessário.

Ao secretário-executivo compete auxiliar o presidente nas sessões plenárias, receber e encaminhar ao Plenário as conclusões do Comitê Assessor, coordenar os trabalhos de assessoramento técnico ao Conselho, propor atividades de intercâmbio de informações, sugerir atividades de C\&T ao Plenário.

\section{Etapas de implantação}

Naturalmente que as idéias mencionadas neste trabalho, para se corporificarem no aludido Sistema, devem ser administradas de maneira seqüencial e participativa com as lideranças científicas locais e o CNPq, visando possibilitar a real eficácia que uma gestão de ciência e tecnologia pode trazer para a máquina burocrática estatal, com o conseqüente repasse de benefícios à população candanga.

- Primeira etapa - cadastramento das entidades em ciência e tecnologia no Distrito Federal, o qual se dará em dois momentos: o primeiro onde se confeccionará um diretório contendo dados gerais, tais como endereço, natureza e vinculação administrativa, documento legal de criação, atuação e objetivos; o segundo onde se listará os projetos e atividades já desenvolvidos, os em desenvolvimento, as equipes técnicas, os equipamentos e laboratórios existentes.

- Segunda etapa - análise dos dados e encaminhamento ao sr. governador da proposta formal de institucionalização do Sistema de CधT.

- Terceira etapa - elaboração de instrumentos legais que permitam a definição de atribuições e mecanismos necessários ao funcionamento do Sistema.

- Quarta etapa - levantamento das necessidades de C\&T através do programa de governo e das ações setoriais do III PBDCT.

- Quinta etapa - elaboração de documentos com subsídios para o desenvolvimento científico e tecnológico do Distrito Federal o qual procurará listar, por área temática as questões que de perto interessem ao governo do Distrito Federal neste campo. Tal documento se pautará no plano de ação do governo, nas diretrizes do Conselho de Ciência e Tecnologia, na demanda dos órgãos partícipes do Sistema e nas orientações contidas no III PBDCT.

- Sexta etapa - criação, no âmbito da Secretaria de Finanças do Distrito Federal, mais precisamente no Banco Regional de Brasília, de um Fundo para o Desenvolvimento da Ciência e Tecnologia no Distrito Federal, a exemplo do exiśtente no Banco do Brasil.

\section{Benefícios que uma eficiente administração da CGT pode trazer para a Capital Federal}

Em primeiro lugar, devemos ressaltar que todo o esforço do componente C\&T, a ser realizado no Distrito Federal, visa ao desenvolvimento harmônico dos aspectos sócio-econômicos de nossa Capital Federal.

Em consonância com a diretriz governamental de privilegiar o homem, nossos programas de C\&T deverão voltar-se para a pesquisa de questões relativas à satisfação de suas necessidades, no que tange à saúde, habitação, alimentação, emprego, locomoção, educação e cultura, assistência social e saneamento prioritariamente, de acordo com o plano de governo do Distrito Federal.

Tal postura, naturalmente irá requerer a cooperação de diversos órgãos de nosso complexo adminstrativo, bem como de instituições de pesquisas e financiamento externas ao mesmo. 
A esse respeito, é interessante ressaltar que só no âmbito do governo local contamos atualmente com quinze órgãos que desenvolvem pesquisas. Considerando que esse número é bastante significativo, devemos enfatizar, porém, a total desarticulação desses órgãos, até a nível setorial, o que redunda em paralelismos de ação e pluralidade de tratamento. Assim a administração dos mesmos, sob a forma sistêmica, os beneficiaria através da integração de políticas e pelo fluxo constante de comunicação.

Por outro lado, existe o reconhecimento da necessidade de se alterar nossa situação de dependência, acentuadamente no campo da tecnologia, em relação a outros centros nacionais, o que possibilitará uma maior aborção de mão-de-obra sofisticada, que hoje ao sair de nossas universidades não consegue aplicar seus conhecimentos em benefício da comunidade brasiliense.

Com isto, além de se poder reverter a tendência do aumento do desemprego, se estará consolidando a cidade, pois o jovem que aqui passou grande parte de sua vida, poderá continuar residindo e trabalhando aqui no Distrito Federal.

\section{Uma política de CGT para o Distrito Federal}

Não nos basta delinear a estrutura, suas funções e atribuições no que concerne à C\&T no DF, mas devemos junto com este desenho pensarmos em um instrumento, em um plano de ação para o setor.

Assim, a política do desenvolvimento científico e tecnológico, a nosso ver, se norteará sempre pela busca da melhoria das condições de vida da população, e objetivará alcançar uma maior capacitação científica, que redundará no incremento da produção científica e tecnológica.

Para a consolidação deste instrumento, é necessário que não nos esqueçamos de que precisamos contar com o concurso de alguns mecanismos básicos, quais sejam: informação em ciência e tecnologia; financiamento e cooperação técnica nacional e internacional.

A política, formalizada através de um plano de ação, deverá contemplar, prioritariamente: otimização do uso de recursos físicos e naturais, tecnológicos e humanos, disponíveis no Distrito Federal; a criação de um programà de formação e desenvolvimento de recursos humanos para a pesquisa; integração das instituições de pesquisa; estabelecimento de uma maior integração entre C\&T e o setor produtivo; proteção ao meio ambiente; articulação com os programas de C\&T nacional e regional; detalha- mento dos diversos setores de atuação da C\&T, tais como, energia, transportes, agropecuária, educação e cultura, saúde e nutrição, assistência social, habitação e saneamento, indústria, comunicações, desenvolvimento regional, desenvolvimento urbano, meio ambiente e recursos naturais, bem como sua priorização, tendo em vista a política do governo do Distrito Federal.

Cabe ressaltar que este roteiro alinhava apenas idéias gerais e que esse detalhamento e complementação se dará através do acionamento de mecanismos participativos, onde todos os órgãos envolvidos deverão ser representados por elementos da área de pesquisa, a fim de que o futuro PBDCT/DF espelhe as aspirações dos diversos segmentos nele contidos.

É fundamental, todavia, o entendimento de que o documento em foco seja seguido da seleção de elenco de programas e projetos a serem implementados.

\section{Informação em C\&T}

Só com a implantação e funcionamento ativo deste canal, se poderá desenvolver a CधT no Distrito Federal, pois é instrumento fundamental no fornecimento de dados para o planejamento e acompanhamento das pesquisas em andamento, bem como acondicionamento das já realizadas.

Cabe ressaltar que o Sistema deverá se apoiar inicialmente no tratamento computadorizado nas estruturas já existentes no governo do Distrito Federal, ou sejam, os canais da Secretaria de Administração e da Companhia do Desenvolvimento do Planalto Central - Codeplan.

Quanto aos usuários das informações, deverá ser-Ihes oferecido um banco de dados, onde eles possam demandar por telefone, telex ou pessoalmente, e receber as matérias solicitadas em curto prazo, e periodicamente os catálogos gerais.

\section{Financiamento}

Deverá ser elaborado um orçamento de C\&T para o Distrito Federal e também captado, em agências e fontes de financiamentos, recursos a serem aplicados em pesquisas no Distrito Federal. Se estimulará, identicamente, a participação das empresas privadas no financiamento da atividade de C\&T, visando complementar os recursos governamentais.

A Financiadora de Estudos e Projetos - Finep, a Coordenação do Aperfeiçoamento de Pessoal de Nivel Superior - Capes, o CNPq e os demais órgãos de fomento à atividade de C\&T deverão ser contactados para o conhecimento da proposta para o setor, a fim de que possamapoiar as atividades futuras dos elos do sistema. 
Cabe ressaltar que no Banco Regional de Brasília se poderá ativar um fundo de incentivo à pesquisa no Distrito Federal, o qual aportará recursos para o setor, sendo que a liberação, seja ela pessoal ou institucional, só será efetivada se o projeto se adequar às prioridades traçadas para o setor, pelo CCT.

\section{Cooperação técnica nacional e internacional}

Será utilizada como um instrumento subsidiário da execução de um plano de desenvolvimento de CधT do Distrito Federal.

A cooperação técnica, a nível nacional se fará sempre que se sentir a necessidade da consultoria, do intercâmbio ou da formação de recursos humanos em tópicos específicos, por exemplo, quando a Fundação Zoobotânica do Distrito Federal estiver estudando pastagens, poderá contactar o departamento que trata do assunto na Embrapa ou quando o Departamento de Estradas de Rodagem do Distrito Federal for pesquisar camada asfáltica ou tamanho ideal de meio-fio poderá intercambiar experiência com o Instituto de Pesquisas Rodoviárias, etc. A missão da Coordenação do Sistema é efetuar a listagem dos órgãos que podem atender ao pleito e o contato, bem como providenciar administrativamente os meios para a interação.

Quanto à cooperação técnica internacional, devido à proximidade geográfica com diversos órgãos internacionais e embaixadas, deve-se promover ampla divulgação das atividades e projetos das entidades partícipes do Sistema, visando auferir os benefícios que uma troca de experiências ou consultoria internacionais pode oferecer ao Sistema. Basta lembrar que aqui se encontram o Instituto Interamericano de Cooperação para a Agricultura - IICA, as representações da Organização das Nações Unidas - ONU e da Organização dos Estados Americanos - OEA, escritórios da Organização das $\mathrm{Na-}$ ções Unidas para a Educação, Ciência e Cultura Unesco e da Organização Internacional do Trabalho - OIT, e outros mais que dentre suas atribuições figura a de cooperar com países em desenvolvimento em diversas áreas, dentre as quais a de pesquisas básicas e aplicadas.

\section{A administração de C\&T como elo de ligação entre a comunidade científica brasiliense e as prioridades governamentais nas áreas social e econômica}

A produção de pesquisas em qualquer área do conhecimento tem como elemento central do pro- cesso o pesquisador, o cientista, o qual se movimenta entre seus pares visando a troca de experiências. Essa categoria é chamada de comunidade científica e sua atuação se caracteriza por regras próprias de desenvolvimento em cada ramo do conhecimento científico; total autonomia acadêmica e pelo compromisso indireto com as prioridades do desenvolvimento sócio-econômico nacional.

A nossa agência de administração da atividade científica no Distrito Federal se caracterizará por enfatizar a prioridade do desenvolvimento social e econômico local pela acurada análise da viabilidade econômica dos projetos e programas e por critérios decisórios externos ao campo científico.

Assim, embora a princípio pareça difícil juntar os discursos oficial e o da comunidade científica, à administração de CधT caberá acoplar os interesses de ambas as partes, tendo em vista um objetivo maior: o desenvolvimento harmônico do Distrito Federal e a Região Geoeconômica de Brasília, tendo sempre em mira que o fim do processo é a melhoria das condições de vida das populações aí existentes.

Figura 2 - Estrutura preliminar do Sistema de Ciência e Tecnologia do Distrito Federal

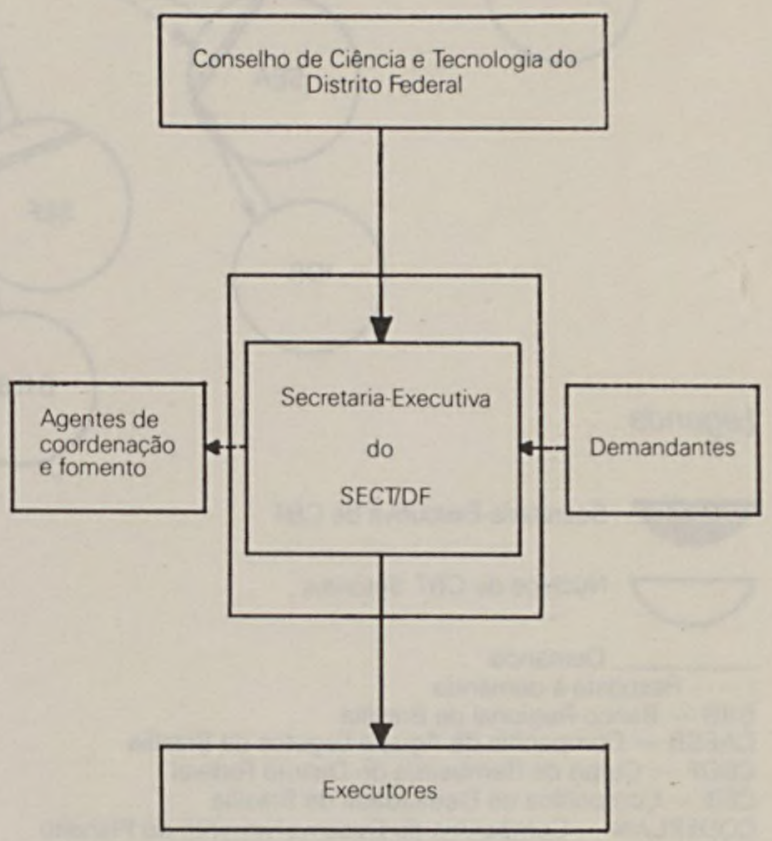

Funçăo da Secretaria-Executiva

gestão do processo global, que compreende coordenação, coleta e sistematização da demanda, articulação. 


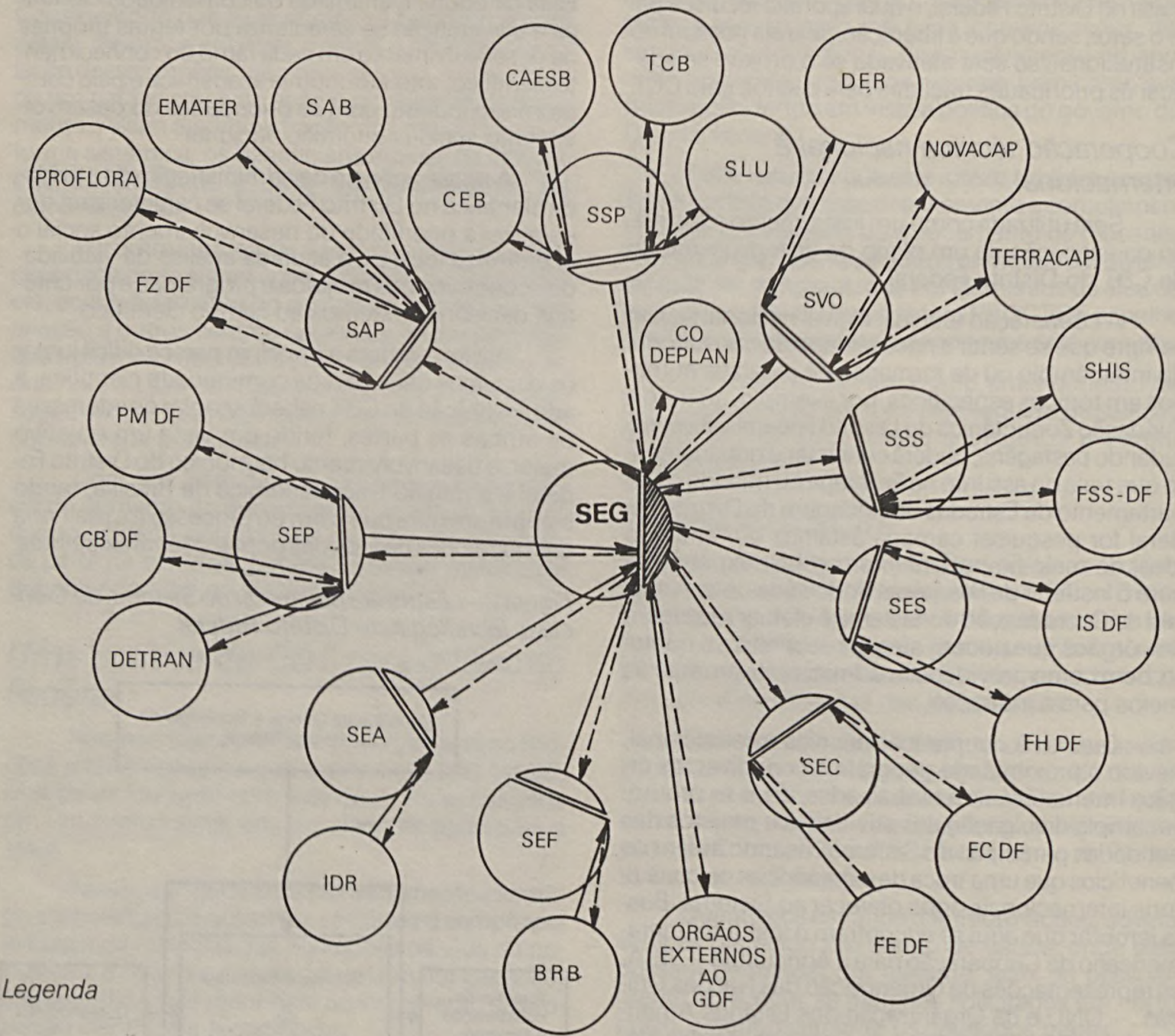

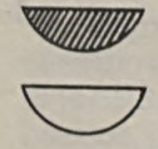

Secretaria-Executiva de C\&T

Núcleos de C\&T Setoriais

Demanda

..... Resposta à demanda

BRB - Banco Regional de Brasília

CAESB - Companhia de Água e Esgotos de Brasília

CBDF - Corpo de Bombeiros do Distrito Federal

CEB - Companhia de Eletricidade de Brasilia

CODEPLAN - Companhia do Desenvolvimento do Planalto

Central

DER - Departamento de Estradas de Rodagem

DETRAN - Departamento de Trânsito

EMATER - Empresa de Assistência Técnica e Extensão Rural

FCDF - Fundação Cultural do Distrito Federal

FEDF - Fundação Educacional do Distrito Federal

FHDF - Fundação Hospitalar do Distrito Federal

FSS - Fundação do Serviço Social

FZDF - Fundação Zoobotânica do Distrito Federal
IDR - Instituto de Desenvolvimento de Recursos Humanos ISDF - Instituto de Saúde do Distrito Federal

NOVACAP - Companhia de Urbanização da Nova Capital do Brasil

PMDF - Polícia Militar do Distrito Federal

PROFLORA, Florestamento e Reflorestamento S/A

$S A B$ - Sociedade de Abastecimento de Brasilia

SAP - Secretaria de Agricultura e Produção

SEA - Secretaria de Administração

SEC - Secretaria de Educação e Cultura

SEF - Secretaria de Finanças

SEG - Secretaria do Governo

SEP - Secretaria de Segurança Pública

SES - Secretaria de Saúde

SHIS - Sociedade de Habitação de Interesse Social Ltda.

SLU - Serviço Autônomo de Limpeza Urbana

SSP - Secretaria de Serviços Públicos

SSS - Secretaria de Serviços Sociais

SVO - Secretaria de Viação e Obras

TCB - Sociedade de Transporte Coletivo de Brasília

TERRACAP - Companhia Imobiliária de Brasília 


\section{Bibliografia}

BRASIL. Leis, decretos, etc. Decreto n. 75.225 , de 15 de janeiro de 1975. D.O.U., 16/1/75, p. 691.

Decreto n. 85.118 , de 3 de setembro de 1980. D.O.U. 168 , 4/9/80, Seção I, p. 17.494-17.501.

BRUNI, Sérgio de A. Considerações sobre o aparato de ciência e tecnologia do Governo do Distrito Federal. In: ANAIS DO VIII - SIMPÓSIO NACIONAL DEPESQUISA EM ADMINISTRAÇÃO DE CIÊNCIA E TECNOLOGIA. São Paulo, Finep/USP, 1983. $5 \mathrm{p}$.

CONSELHO NACIONAL DE DESENVOLVIMENTO CIENTIFICO ETECNOLÓGICO. Guia para obtenção de recursos nas principais fontes de financiamento à ciência e tecnologia. Brasília, $1982.100 \mathrm{p}$.

Sistemas estaduais de ciência e tecnologia; concepção e diretrizes operacionais. Brasília, 1981. 50 p.
DIRETÓRIO de entidades atuantes em ciência e tecnologia no Distrito Federal. Brasília, MIC, STI/Embrapa, 1982. 134 p.

HANIKA, F. de O. Guia moderno de administração. Rio de Janeiro, Forense, 1965.90 p.

MARCOVITH, Jacques. Seminário sobre ciência e tecnologia. São Paulo, USP, 1982.

NASCIMENTO, Kleber. A revolução conceptual da administração; implicação para a formulação de papéis e funções essenciais de um executivo. Rio de Janeiro. Rev. de Administração Pública, 1972.

ORGANIZATION DE COOPÉRATION ET DÉVELOPPMENT ÉCONOMIQUE - OCDE. Medição de atividades cientificas e tecnológicas; Manual Frascati. Trad. de Iremar Bronzeado. Brasília, CNPq, 1978. 150 p.

SCHWARTZMAN, Simon. Coord. Administração da atividade científica. Brasília, Finep/CNPq, 1981. 78 p. 